\title{
A EXTENSÃO NOS CURSOS DE LICENCIATURA DA UNIVERSIDADE FRANCISCANA, SANTA MARIA, RS, BRASIL: NARRATIVAS DE ACADÊMICOS (AS) INTERVENTORES (AS) NOS TERRITÓRIOS EDUCATIVOS ${ }^{1}$
}

\author{
EXTENSION IN FRANCISCAN UNIVERSITY'S LICENTIATE COURSES, \\ IN SANTA MARIA, RS, BRAZIL: NARRATIVIES OF INTERVENTING \\ STUDENTS IN EDUCATIONAL TERRITORIES.
}

\section{Ail Conceição Meireles Ortiz ${ }^{2}$, Deividi Fernando Borges da Cunha ${ }^{3}$, Diego Maia Miranda Erick Kader Callegaro Correa ${ }^{5}$, Leandro Pereira Quevedo ${ }^{6}$, Liane Batistela Kist ${ }^{7}$, Juliane Marschall Morgenstern ${ }^{8}$, Marcio Tascheto da Silva9 e Pedro Angelo Miri ${ }^{10}$}

\section{RESUMO}

Este artigo apresenta narrativas de acadêmicos de Cursos de Licenciatura da Universidade Franciscana, Santa Maria, RS, em torno das intervenções realizadas nos anos 2020/2021, sobre os territórios educativos. A educação superior tem como função maior a geração de saberes, por meio do ensino, pesquisa e da extensão universitária. A extensão universitária suscita a compreensão da atividade acadêmica, também, como consequência natural, da instauração de uma ambiência dialógica e de coparticipação entre uma agência geradora de saberes científicos e instituições comunitárias, produtoras de saberes socioculturais. A forma linguística de pronúncia do nosso pensamento diante dos objetos e ações, constitui a narrativa. Por meio de narrativas os estudantes passaram a retratar interpretações de processos sócio-históricos, culturais e educacionais, que para conhecer e compreender, diante de intervenções extensionistas. A vivência extensionista afirma fortes contribuições acadêmicas e profissionais para o fortalecimento da formação docente, uma vez que, a inserção sobre os territórios educativos, sejam eles escolares e/ou não escolares, lhes garante o conhecimento da realidade socioeducacional.

Palavras-chave: Extensão; Saberes docentes; Formação acadêmica; Comunidade.

\section{ABSTRACT}

This article presents the narrative of licentiate courses' students from the Franciscan University, in Santa Maria, RS, whose theme is about the interventions upon education territories. Higher learning education has as a broader function to generating knowledge through teaching, research and extension. The university extension triggers the acknowledgement of academic activity as a natural consequence of the instauration from

1 Artigo acerca de narrativas de acadêmicos (as) em intervenção extensionista em Curso de Licenciatura/UFN, Santa Maria, RS, Brasil.

2 Coordenadora da Curricularização das Licenciaturas/UFN, Santa Maria, RS. E-mail: ail@ufn.edu.br 3 Acadêmico do Curso de Pedagogia/UFN, Santa Maria, RS. E-mail: deividifernando@ufn.edu.br 4 Acadêmico do Curso de História/UFN, Santa MAria, RS. E-mail: diegomaiamiranda@yahoo.com.br 5 Coordenador do Curso de Letras/UFN, Santa Maria, RS. E-mail: erick@ufn.edu.br 6 Egresso do Curso de Letras/UFN, Santa Maria, RS. E-mail: leandro@ufn.edu.br 7 Docente do Curso de Letras/UFN, Santa Maria, RS. E-mail: lianekist@ufn.edu.br 8 Docente do Curso de Pedagogia/UFN, Santa Maria, RS. E-mail: julianemm@ufn.edu.br 9 Docente do Curso de História/UFN, Santa Maria, RS. E-mail: marciotascheto@ufn.edu.br 10 Acadêmico do Curso de Filosofia/UFN, Santa Maria, RS. E-mail: pedro.miri@ufn.edu.br 
the dialogic ambience and co-participation between a scientific knowledge generating agency and community institutions, which produce sociocultural knowledge. The linguistic pronunciation of our thought in front of objects and actions constitutes a narrative. Through narratives, students are able to interpret sociohistorical, cultural and educational processes that recognize and comprehend the extension interventions in themselves. The extension experience affirms strong academic and professional contributions to the strengthening of the student formation once the insertion in educational territories, whether formal or not, guarantees knowledge from the socioeducational reality.

Keywords: Extension; Student knowledge; student formation; community.

\section{INTRODUÇÃO}

A educação superior congrega importantes funções formativas à constituição dos perfis profissionais a serem integrados sobre o mundo do trabalho. Este mundo do trabalho representa uma realidade sócio-histórica e cultural diante de um contexto amplo e dirigente, desenhado por firmes lógicas sociais, economicistas e políticas, éticas e técnico-científicas em ritmo acelerado de transformação.

Novas tendências e perspectivas passam a se anunciar a uma pedagogia universitária, em que coloque a extensão, como importante membro gerador de conhecimentos contribuintes à formação de profissionais, e em especial, docentes, para que passem a conhecer, em tempo de academia, e a pensar sobre o que veem nos territórios, espaços sociais, escolares e não escolares, compreendendo-os como potenciais campo de ensino e aprendizagem. Este pensar sobre situações problematizadoras, que representam o espaço educacional, em tempo de vida universitária, reafirma efetivamente, a dimensão agregadora e interdisciplinar, que se configura, a relação teoria e prática. A base conceitual e metodológica construída pelo ensino, garante este pensar analítico fundamentado, ao longo da prática investigativa, possibilitada pela extensão. Ou seja, ensino, pesquisa e extensão articuladas na atitude de raciocinar em movimento de construção, desconstrução e reconstrução, diante da realidade socioeducacional, campo de atuação do futuro professor.

\section{DIMENSÕES FUNCIONAIS DA UNIVERSIDADE, FORMAÇÃO DOCENTE E A CURRICULARIZAÇÃO DA EXTENSÃO NOS CURSOS DE LICENCIATURA DA UNIVERSIDADE FRANCISCANA, SANTA MARIA, RS, BRASIL}

O ensino, a pesquisa e a extensão compõem as funções da universidade. O ensino se constitui em relação à aprendizagem. Esta relação implica em uma mediação dialética e dialógica entre professor/aluno e conhecimento. Segundo Libâneo (1994, p. 90):

A relação entre ensino e aprendizagem não é mecânica, não é uma simples transmissão do professor que ensina para um aluno que aprende. Portanto é uma relação recíproca na qual se destacam o papel dirigente do professor e a atividade dos alunos. " Dessa forma podemos perceber que "O ensino visa estimular, dirigir, incentivar, impulsionar o processo de aprendizagem dos alunos. 
A pesquisa compreende o movimento do conhecimento da realidade e a promoção de possibilidades concretas de soluções a questões da vida humana impõem atitude crítico-reflexiva, diante de ações investigativas, como condição para diagnósticos concretos à obtenção de alternativas criativas ao cotidiano instável da sociedade. Para Herrera (1996 apud LAMPERT, 2000, p. 16), a universidade não somente prepara para a vida profissional, mas também tem como missão à investigação, à busca de novas técnicas, novos produtos e novas aplicações. O espaço acadêmico tem o compromisso de fomentar e compartilhar, a partir da dimensão da pesquisa, do ensino e da extensão, a formação inicial aos futuros profissionais de todas as áreas. A educação superior, espaço consagrado pela construção de novos conhecimentos, possibilita a inserção sobre processos formativos em múltiplas atividades profissionais, abrangendo variadas áreas do conhecimento humano.

Este compromisso se traduz na proposta de ações, que atinjam o fazer pedagógico, como um processo histórico, social e cultural, que se constrói e se reconstrói, permanentemente, com vistas à qualidade educativa em ambiência acadêmica. A extensão universitária, em destaque, suscita a compreensão da atividade acadêmica, também, como consequência natural, da instauração de uma ambiência dialógica e de comparticipação entre uma agência geradora de saberes científicos e instituições comunitárias, produtoras de saberes socioculturais. Esta dialogicidade vai além de um repasse de produções intelectuais, sobre uma dimensão assistencialista e deliberativa; e sim, deve ser compreendida diante de uma eficiência social compartilhada. Diante do contexto da educação superior, estão os Cursos de Licenciatura.

Os cursos de formação de professores manifestam a oportunidade de preparação de profissionais que exerçam a atividade docente em postura reflexiva, crítica e proativa. Este exercício reflexivo integra o desenvolvimento de habilidades e competências docentes, diante de práticas acadêmicas instigantes, investigativas e propositivas, promovendo a construção de alternativas fundamentadas, que formem para a capacidade de redimensionar as trajetórias pedagógicas. Esta atitude se caracteriza pelo estabelecimento de um verdadeiro processo de investigação/resposta ao contexto escolar contemporâneo e ao atendimento aos múltiplos contextos socioculturais, com vista à mobilização e a construção de conhecimento. A qualidade educativa escolar reflete acima de tudo a qualidade dos processos formativos dos educadores. A ação docente constrói-se, como uma composição de saberes e fazeres qualificada por uma fundamentação teórico-metodológica, em tempo de graduação universitária, aliada a um conjunto de formulações elaboradas em serviço profissional e qualifica-se na medida em que o conhecimento produzido conecta-se com as práticas sociais recorrentes na contemporaneidade, propondo inovações e mudanças significativas no devir humano. A atividade educativa realiza-se entre seres humanos; portanto, a função do professor está vinculada, tanto à formação acadêmica, por meio da socialização do conhecimento técnico científico, quanto ao que se refere à formação da cidadania.

O espaço acadêmico é qualificado por possibilidades de troca entre escola e universidade, garantindo a construção coletiva de novos conhecimentos. O planejamento da prática pedagógica 
escolar abrange o conhecimento sócio-histórico-educacional da realidade sobre a qual ocorrerá o processo de ensino e aprendizagem, assim, atividades acadêmicas voltadas à extensão, pesquisa e ensino preparam, em curso formativo, para a prática docente em situação profissional.

A concepção de curricularização da extensão, traz, em seu conjunto, a complexidade e a integralização da operação conjunta dos sentidos do ensino, da pesquisa e da própria extensão. Curricularizar a extensão compreende a inclusão da dimensão extensionista sobre as disciplinas curriculares dos Cursos, de forma que as ações ocorram sobre a articulação aos Programas de Extensão Institucionais, à proposta pedagógica do Cursos e às demandas da comunidade ou dos territórios sobre os quais se darão às intervenções. Estas práticas curriculares deverão estar atendendo ao contexto sócio-educacional e cultural da temporalidade em que forem planejadas e desenvolvidas. As ações de caráter extensionista, sobre nos Cursos de Licenciatura da UFN, vêm se desenvolvendo por meio de subprojetos, alinhados a um ou mais Programas de Extensão Institucional e ao Projeto de Extensão Integrador. São executadas sob a forma de subprojetos, alinhados a um ou mais Programas de Extensão Institucional e ao Projeto de Extensão Integrador. As ações extensionistas, nos Cursos de Licenciaturas, integram o Programa Educação, Cultura e Comunicação. O Projeto de Extensão Integrador das Licenciaturas abrange o tema Integração Universidade/Escola/ Comunidade, sendo desenvolvido por subprojetos, a cada semestre dos Cursos, por meio de disciplinas extensionistas, mobilizados pelas disciplinas de Seminários Integradores. Estas disciplinas integram o currículo das Licenciaturas, focando em temáticas pontuais. O Seminário Integrador I destaca o tema investigação e contextualização da realidade social; o Seminário Integrador II, relações interpessoais na comunidade escola; o Seminário Integrador III, sistemas de ensino e mecanismos de gestão; o Seminário Integrador IV, atuação em ambientes não formais; o Seminário Integrador V, modalidades de ensino e diversidades; o Seminário Integrador VI, pesquisa em cenários diversos e o Seminário Integrador VII, focaliza atividades integradoras com a comunidade escolar. A operacionalização desta estrutura curricular se dá pela definição de sujeitos e respectivas atribuições a serem desenvolvidas.

\section{NARRATIVAS DOS LICENCIANDOS EM INTERVENÇÃO SOBRE OS TERRITÓRIOS EDUCATIVOS}

O processo comunicacional entre os seres humanos se dá pela linguagem, seja ela por produções escritas e/ou orais. A linguagem expressa os sentidos manifestados por vivências entre seres humanos, sobre um contexto espaço-temporal, de forma a traduzir uma realidade interpretada pelo pensamento humano. Esta forma linguística de pronúncia do nosso pensamento diante dos objetos e ações constitui a narrativa. Segundo Souza (2006), a narrativa possibilita ao sujeito questionar-se sobre seus saberes de si, pois permite ao narrador debruçar-se sobre sua história e sobre seu saber.

A inserção diante de atividades extensionistas promoveu a emergência de importantes saberes 
que resguardam descobertas individuais e coletivas à cada universitário (a). Em trânsito sobre um verdadeiro laboratório vivencial, o qual representa a realidade socioeducacional, os acadêmicos (as) passam a investir sobre processos auto formativos e formativos, que lhes resguardam aprendizados essenciais à constituição da profissão docente. Os territórios, recortes espaciais de intervenção extensionista, os aproximam, em curso formativo, aos diferentes desenhos de estruturas escolares e não escolares.

A voz dos licenciandos, por meio de seus discursos, ao longo e, até mesmo, após as incursões extensionistas, retratam interpretações de processos sócio-históricos, culturais e educacionais que passaram a conhecer e compreender. Para Orlandi,

O conceito de discurso é o da linguagem em interação, ou seja, aquele em que se considera a linguagem em relação às suas condições de produção, ou dito de outra forma, é aquele em que se considera que, a relação estabelecida pelos interlocutores assim como o contexto, são constitutivos da significação de que se diz. Estabelece-se, assim, pela noção de discurso, que o modo de existência da linguagem é social: lugar particular entre língua (geral) e fala (individual), o discurso é lugar social. (ORLANDI, 2005, p. 157)

A linguagem amplifica a compreensão de sua função, portanto, não apenas, como uma autodescrição, mas acima de tudo, expressa uma escrita social, consubstanciada em historicidade.

Algumas narrativas são apresentadas a seguir, com o objetivo de evidenciar aspectos relacionados à autocompreensão da função docente, em suas diferentes áreas de habilitação e impressões e contribuições da extensão universitária sobre os processos acadêmicos de formação para a docência futura. Respeitando a privacidade dos discentes, utilizamos a seguinte nomenclatura: Licenciando e a letra de seu primeiro nome (doravante, Licenciado X).

a) Licenciando D: Sou aluno do Curso de Pedagogia, do terceiro semestre. O que entendo, como função do pedagogo para a formação humana? A Pedagogia, ao longo dos anos, vem nos mostrando, que o aluno não é uma mera tábula rasa, não é um simples repositório, mas sim, algo mais complexo. O aprendente não é apenas um espectador mas sim, o protagonista de sua própria aprendizagem. O Curso de Pedagogia tem apresentado, importantes teóricos, como Rousseau, Pestalozzi, Froebel, Dewey, Montessori, Freinet, Malaguzzi, Wallon, Piaget, Vygotsky, Freire e seus estudos em diferentes épocas. À cada nova descoberta e novos estudos, resultaram na evolução dos saberes sobre as crianças, que passaram a contribuir e contribuem ainda, para o entendimento da aprendizagem humana. Isto, só foi possível, graças a pedagogos e pedagogas, que se dedicaram em descobrir e estudar, como se dá o processo de construção da aprendizagem, e, assim, poderem colaborar no desenvolvimento do ensino aprendizagem, não como um mestre, que transfere seu conhecimento, mas sim, como um facilitador, que ajuda no desenvolvimento do aluno. Ser um pedagogo, é ser um cientista da aprendizagem e, sem esses profissionais não seria possível existir o novo, seríamos mera réplicas do que já existe, sem qualquer criatividade e sem qualquer possibilidade de nos tornarmos melhores. Seríamos o mesmo de ontem. A curricularização da extensão universitária vem obtendo destaque no 
meio acadêmico. Entendida como promotora da interação transformadora entre Universidade e sociedade. Os professores formadores, assim como os alunos, futuros professores devem caminhar juntos no processo de formação universitária e, que o resultado dessa aprendizagem seja compartilhado com a sociedade. Em outras palavras, com o território. A extensão vem nos demonstrar, que no território, estão os maiores desafios, tanto na pesquisa, quanto nas experiências que o território possa nos proporcionar. Mas se faz necessário entender, que o território, não é um simples objeto de aprendizagem, que se possa colocar em um microscópio para ser estudado e experienciado. É preciso ir mais além, o aluno universitário, o professor e a Universidade, juntos com a comunidade e os agentes administrativos eleitos pelo povo, precisam buscar, por meio de suas práticas e seus estudos, uma melhoria na vida das pessoas do território onde estão inseridos. Assim, estarão em atitude de ajuda para uma transformação social, de dentro para fora e não mais, só de fora para dentro, para que cada rua, bairro, distrito, cidade possam resolver seus problemas mais urgentes. Se faz necessário essa integração entre a Universidade e o território. As Universidades, inseridas em uma realidade histórica, política e social, devem atuar e intervir neste contexto. As Universidades, seus professores e alunos só têm a ganhar com a curricularização da extensão. Quando essa prática é bem desenvolvida, ela produz uma sociedade mais justa e igualitária. Penso que o ensino, pesquisa e extensão, que são as bases de uma Universidade, deve ter um maior compromisso social, para uma transformação mais efetiva, e porque não dizer urgente! $\mathrm{E}$, que nesse processo, o aluno aprenda, tanto na sala de aula, como na prática, porque é no território, que ao longo de seu contínuo processo de aprendizagem, o futuro profissional encontrará seus maiores desafios. A Universidade, como agente formador, precisa ter como foco, a formação de alunos investigativos, críticos e observadores. Com um olhar empático para poder interagir diretamente com a sociedade. A extensão universitária, assim como, o que aprendi com meus professores, foi para mim, um despertar, de como uma Universidade pode e deve ser transformadora na formação profissional e na vida de um sujeito. Foi como acordar de um longo sono. Esse despertar, me fez compreender que tenho direitos, que tenho deveres, mas o que mais me transformou foi entender, que não sou simplesmente, um passageiro no território, que não posso simplesmente, esperar, que as mudanças caiam do céu e como, num passe de mágica, os problemas sociais sejam resolvidos. Tudo passa por um processo e, o primeiro passo desse processo, era me reconhecer como protagonista da minha vida, artífice da minha história, e que tudo é possível. Não somos seres nascidos em casta, limitados ao nascer, sem escolhas e destinados a viver uma realidade que não escolhemos, e, simplesmente, aceitar nossa sorte. Hoje, me vejo capaz de buscar algo melhor para minha vida, para minha família e para as pessoas, que se encontram na mesma realidade social.

b) Licenciando D: Sou acadêmico do curso de História, da Universidade Franciscana- UFN, estou cursando o oitavo semestre de História. O curso destaca-se na formação de docentes para o ensino fundamental, médio e superior, público e privado, é também relevante na formação de pesquisadores para atuação em museus, arquivos, centros culturais e de patrimônios históricos. A História é 
um campo fascinante do conhecimento. Nela podemos perceber, registros sobre as culturas, as nações e os personagens, que marcaram o desenvolvimento das civilizações, desde os primeiros tempos até os dias de hoje. Muito mais do que somente documentar o passado, a História permite que o conhecimento sobre as ações ocorridas em determinadas épocas sirva de alguma forma em nosso tempo presente, para que possamos melhor compreender os momentos atuais. Então, o desenvolvimento social, as ideias, os inventos e o cotidiano das populações de outros tempos, os fatos relevantes, que serviram para direcionar, ou até mesmo, redirecionar os caminhos da humanidade, são também ressaltados e trabalhados em detalhes. A História não se restringe ao espaço da educação ou à pesquisa acadêmica. A importância do profissional de História, para a formação humana, é manter um senso crítico apurado, acerca do que está acontecendo na sociedade, que permita a apreciação dos eventos históricos com o rigor científico necessário, para poder auxiliar a sociedade na compreensão do tempo presente. É importante ressaltar, que o educador histórico mantenha o compromisso com a ética, e que possa esforçar-se para o desenvolvimento de uma formação interdisciplinar, que permita interagir com os outros conhecimentos acadêmicos. Uma das atividades de maior importância no curso de História, é sem dúvida a extensão, pois nos possibilita uma conexão entre a Universidade e a sociedade, que dentro do conceito, da educação continuada, atendem a um perfil heterogêneo de pessoas. Podemos dizer que a extensão é um instrumento para uma relação virtuosa entre a Universidade e a sociedade, e assim, possibilita ganhos para ambas as partes. Por esse motivo, dizemos que a sociedade se beneficia com a extensão universitária, pois constitui meios para que se tenha um compartilhamento de conhecimentos entre a Universidade e um amplo conjunto de atores. O programa objetiva promover a curricularização da pesquisa e da extensão ao longo da formação acadêmica e, assim, promover o debate entre a Universidade e a comunidade. De acordo com Chaú (2001, p. 35) a Universidade deve ser considerada como "uma instituição social”, isso significa que ela realiza e exprime de modo determinado a sociedade de que faz parte. Não é uma realidade separada e sim, uma expressão historicamente determinada de uma sociedade determinada". Podemos considerar que isso nos remete a refletir sobre o ensino superior brasileiro, que desde sua concepção, ocorre por meio de uma interação social. A extensão é de vital importância para a sociedade, pois podemos realizar uma troca com a comunidade, levando o conhecimento acadêmico para as pessoas que não estão inseridas dentro das Universidades, buscando uma interação, uma troca, pois estas pessoas têm o seu conhecimento adquirido. Com a extensão podemos trazer à tona questões que estavam esquecidas, em certa comunidade. "A cidade é um campo rico de pesquisa e aprendizado, um meio grandiosamente interdisciplinar que precisa ser explorado pelos professores" (COSTA, 2006, p. 99). Extensão é um processo vital para obtermos, enquanto acadêmicos, um maior conhecimento, não só de colocar em prática o que se aprende dentro das Universidades, mas de conhecer o que está a nossa volta, pois sair dos muros, da Universidade, e ter o contato com a comunidade da nossa cidade, como no caso do projeto de extensão que foi realizado no Clube de Futebol, Esporte Clube Internacional de Santa Maria, RS, 
recuperando a história do clube, trazendo os torcedores, para dentro do clube. A história de um clube de futebol está entrelaçada com a história da cidade a qual pertence e também com sua comunidade. E assim, propor o acesso ao acervo do E.C. Internacional de Santa Maria. Trazer a comunidade a fazer parte desta História, com a ajuda dos alunos da UFN, recuperando o acervo documental do clube.

c) Licenciando L: Sou graduado em Letras/Língua Portuguesa, pela Universidade Franciscana de Santa Maria, RS, desde 2020. A minha contribuição com este trabalho se dará pelo relato de algumas de minhas experiências, acerca da extensão universitária. Também, apresentarei algumas ideias sobre as funções de um professor da minha área, que considero relevante pensarmos "neste futuro", e que significado a extensão tem para mim. Desse modo, começo-me pelos últimos até o relato da prática desenvolvida no final de 2020. "O medo é a extrema ignorância em momento muito agudo" (ROSA, 1962). Mas o que tem a ver o medo do médico no conto de Guimarães Rosa, que temia a reação de Damásio Siqueira, um bandido, quando lhe perguntou o significado da palavra 'famigerado', com o relato? Tudo, se compreendermos, que a ignorância pode ser a causa das possíveis ações equivocadas de um ser humano. Assim, o professor auxilia o estudante na busca por conhecimento, instigando-o. E, o que existe por trás das palavras que mencionamos? Para responder a essa pergunta, deve-se "ampliar a ideia de texto por meio da modalidade/modulação" (RIBEIRO, 2016), isto é, o homem representa os seus pensamentos por meio de muitos recursos, por isso é necessário ampliar a visão sobre as linguagens. A extensão para mim, ainda que limitada, teoricamente, deve promover a orientação dos estudantes na aquisição ou transformação dos conhecimentos. Entendo, que todos chegam às salas de aula com algum nível. Conforme Paulo Freire (1983) defende, as nossas ações são "transformadoras" da realidade, e devemos admitir, também, que a educação popular favorece para uma autonomia do povo, que se reflete no poder popular. O que significa, que as Universidades devem dialogar com os sujeitos dos territórios, bem como, devem estar inseridos no Ensino Superior. Somente assim, no meu entender, e de acordo com o autor, poderia existir um diálogo entre a Universidade e a sociedade. Neste sentido, a partir de agora, apresento ao leitor uma prática extensionista. Ela foi desenvolvida no segundo semestre de 2020, como produto da disciplina curricularizada, chamada Seminário Integrador IV: atuação em ambientes Não Formais, ministrada pelo professor Marcio Tascheto da Silva. A disciplina continha estudantes de todas as Licenciaturas da Universidade Franciscana, de Santa Maria, RS. Assim, a relação dialógica entre o professor e seus aprendizes na construção do conhecimento, enriqueceu-se com as perspectivas das diversas áreas acadêmicas, que se organizaram em quatro grupos para as investigações dos territórios e a produção dos podcasts. A prática se iniciou com uma investigação limitada pelos territórios entre a Av. Rio Branco até a Gare, na mesma cidade, mas se restringiu por conta dos dados coletados serem relevantes para a série de podcasts, com quatro episódios, que era o nosso objetivo. Após um mapeamento dos territórios, que foi chamado pelo professor de "tour digital", por conta da impossibilidade do contato presencial com as pessoas destes espaços, que a pandemia por Covid-19 nos impôs, reconheceu-se, que tínhamos um 
conciso trabalho, se déssemos atenção para a Vila Belga e a Gare. Felizmente, todos os nossos estudos e produções foram desenvolvidos utilizando a internet e as reuniões remotas. Ao passo, que íamos registrando, por meio dos textos avaliativos para serem entregues ao professor, nas aulas que debatíamos os temas teóricos, identificaram-se os possíveis convidados a falar sobre suas experiências, que contribuíram para a identidade daqueles territórios. Então, os quatro episódios ganharam seus nomes: Memória dos passos perdidos ( $1^{\mathrm{o}}$ episódio), Cidade do agora ( $2^{\circ}$ episódio), Vozes da Beira do Trilho ( $3^{\circ}$ episódio) e Vai dar Bric ( $4^{\circ}$ episódio). Por conta do tamanho e dos desafios, criou-se um grupo de líderes, com representantes de cada grupo para dar mais agilidade na construção dos roteiros e gravações, assim, passaríamos para o segundo passo: as edições. Mas, os roteiros precisavam de ajustes, então, um estudante, juntamente com o professor, "lapidaram” todos eles, de modo a criar uma linearidade ou um fio condutor, que conduziria os ouvintes ao "passeio". Logo, iniciaram-se as gravações dos podcasts de cada grupo. Muitos ajustes foram necessários, como os consertos, gravações e as regravações. Mas, quando ouvimos pela primeira vez as falas dos convidados, algo nos tocou a alma, principalmente, aquelas do episódio três e quatro: encontramos neles aquilo que Carnoy e Gadotti (2018, p. 220) afirmam sobre a produção acadêmica: "deve ser capaz de contribuir com a melhoria das condições da vida da população", pois poderíamos dar notoriedade à voz daqueles sujeitos. No episódio três, um morador relatou sua experiência em uma ocupação em busca de moradia para a sua família. No episódio quatro, um professor de Filosofia liderou um projeto que influenciou na situação econômica do território e das famílias, por meio da venda dos produtos artesanais, ou seja, um líder comunitário. No entanto, os episódios um e dois trataram de contextualizar os territórios da Vila Belga e da Estação Férrea da Gare, bem como, a abordagem de "uma disciplina extensionista ao tratar os espaços da Gare e da Vila Belga, como objetos de estudo e desenvolvimento de intencionalidades educativas, partindo do reconhecimento dos processos de aprendizagens", conforme o podcast. Por fim, concluíram-se os roteiros, as gravações e as edições finais. Os líderes do grupo receberam os roteiros "alinhados" e gravaram os áudios que, ao passo que finalizaram as gravações, encaminharam ao editor Guilherme Ferraz, que infelizmente, faleceu em abril de 2021, vítima da Covid-19. Depois, com necessidade de uma finalização mais apurada, o acadêmico Alan da Comunicação concluiu as edições dos podcasts para a divulgação futura, após a reunião das autorizações. A extensão me fez conhecer territórios e sujeitos com olhos de estudante, apesar de conhecimentos limitados. Também, fez-me um sujeito ativo, mesmo que por pouco tempo, e sem o contato presencial, ensejou novas escolhas com as tecnologias. Enfim, a ideologia de que alguns mencionam pejorativamente, na prática, Paulo Freire fez mais pela educação do que qualquer um, pois é o construtor do caminho, que, no mínimo, deve ser conhecido pelos acadêmicos na extensão.

d) Licenciando P: Sou acadêmico do Curso de Filosofia da Universidade Franciscana (UFN) Santa Maria, RS, atualmente cursando o terceiro semestre da graduação. Tendo como disciplina extensionista Seminário Integrador, quando a constituição Brasileira de 1988 estabeleceu a 
“indissociabilidade entre ensino, pesquisa e extensão[1]” (BRASIL, 1988, Art ${ }^{\circ}$ 207), tendo contato com mais realidades, com as diferenças e outras perspectivas, estimulando o aluno à integração junto à sociedade. Relatarei experiências e estudos realizados durante a formação acadêmica até o tempo presente, após apresentarei a contribuição da Filosofia para a formação humana e as contribuições da extensão para a sociedade e para a formação profissional na solidificação. A extensão nos cursos de licenciatura surge e exige a "redefinição de Universidade, de projetos de curso, a partir de critérios epistemológico-pedagógico[...] (MELLO E NETTO, 2020 p. 19) e, de acordo com essa relação Universidade/sociedade, também se dá no âmbito filósofo na formação humana desenvolvendo um ser mais crítico e compromissado com a comunidade acadêmica e social, ou seja, deve "existir um círculo virtuoso entre os gestores universitários responsáveis pelo ensino, pesquisa e extensão" (MELLO E NETTO, 2020 p. 19). A filosofia na formação humana ligado à extensão acontece, quando "se realiza, com êxito, a interligação entre três dimensões da realização humana: a pessoal, a profissional e a social" (ALARCÃO, 2001 p. 12), gerando relações, afetos comprometimentos e conhecimentos de forma ética entre o educando e os meios social. $\mathrm{O}$ artigo $3^{\circ}$ da resolução número 7 ; de 18 de dezembro de 2018, aborda a Extensão na Educação Superior Brasileira da seguinte maneira:

\begin{abstract}
A Extensão na Educação Superior Brasileira é a atividade que se integra à matriz curricular e à organização da pesquisa, constituindo-se em processo interdisciplinar, político educacional, cultural, científico, tecnológico, que promove a interação transformadora entre as instituições de ensino superior e os outros setores da sociedade, por meio da produção e da aplicação do conhecimento, em articulação permanente com o ensino e a pesquisa. (Ministério da Educação; Art $3^{\circ}$ )
\end{abstract}

De acordo com os termos, a Universidade deve estar atenta e se tornar um locus público de acolhimento das demandas da sociedade, visando aproximar e ver as necessidades públicas sociais, sendo assim precisa tem uma inter-relação com outros setores da sociedade, com a investigação social em várias realidades tendo em vista um bem comum e um olhar para o próximo, preenchendo as maiores lacunas básicas da necessidade social. A extensão tem por obrigação "no mínimo, 10\% (dez por cento) do total da carga horária curricular estudantil dos cursos de graduação, as quais deverão fazer parte da matriz curricular dos cursos" (Ministério da Educação; Art 4º), gerando uma maior atuação transformadora, voltada para os interesses e necessidades da maioria da população, e propiciadora dos desenvolvimentos social e regional e de aprimoramento das políticas públicas no território. O papel da extensão universitária é ter uma atuação "fora dos muros" levando os discentes à sociedade atual, "a interação do diálogo por meio da troca de conhecimentos" (Ministério da Educação; Art $5^{\circ}$ - I), buscando integrar universidades e espaço em atividades que sejam comuns a elas, buscando um público interno e integrante com a ótica voltada ao território, como ele está neste solo, qual as suas necessidades, como as pessoas trabalham, quais são as condições de vida, qual é sua expectativa de vida etc. A extensão auxilia na "busca à formação cidadã dos estudantes, marcada e construída pela 
vivência dos seus conhecimentos" (Ministério da Educação; Art $5^{\circ}$ - II), gerando uma maior "interdisciplinaridade, de forma a integrar a instituição de ensino aos demais setores da sociedade" (MELLO E NETTO, 2020 p. 18). O ensino não deve limitar somente em ensino-pesquisa, mas de transformar na indissociabilidade do ensino, pesquisa e extensão, dando mais conhecimento ao estudante o objetivo da sua formação e para quem está se formando, tendo uma articulação entre teoria e prática.

\section{CONTRIBUIÇÕES DA EXTENSÃO NA FORMAÇÃO ACADÊMICO-PROFISSIONAL DOS ESTUDANTES UNIVERSITÁRIOS DE CURSOS DE LICENCIATURA. ALIANÇAS E CONSOLIDAÇÕES FORMATIVAS}

Que saberes docentes e socioeducacionais foram possíveis avistar, por meio da promoção de interlocuções significativas entre a intencionalidade em efetivar uma ação extensionista sobre bases dialógicas e horizontais entre Universidade e territórios, e a possibilidade de acreditar na emergência do autoconhecimento, da autonomia intelectual, da curiosidade epistemológica, da tomada de consciência de se constituírem também sujeitos históricos e da corresponsabilidade social entre os estudantes?

Este estudante licenciando, que experimentou a vivência extensionista, sobre um planejamento e acompanhamento docente, rigoroso, sistemático e coerente à concepção de extensão, por um paradigma dialógico e dialético, já se mostra, pelas próprias narrativas, um sujeito histórico reflexivo, crítico e autocrítico, compreensivo e auto compreensivo, ator e autor. Os processos formativos devem atentar à formação de educadores pesquisadores, para que estejam preparados à atitude constante de diagnosticar perfis de seres humanos com os quais irão conviver e aprender mutuamente. Nóvoa afirma que (1992, p. 110),

\footnotetext{
$\mathrm{Na}$ vida profissional, o professor defronta- se com múltiplas situações para as quais não encontra respostas pré-elaboradas e que não são susceptíveis de serem analisadas pelo processo clássico de investigação científica. Na prática profissional, o processo de diálogo com a situação deixa transparecer aspectos ocultos da realidade divergente e cria novos marcos de referência, novas formas de perceber e de agir. A criação e construção de uma nova realidade obrigam a ir para além das regras, fatos, teorias e procedimentos conhecidos e disponíveis.
}

O educador em formação compreende um ser humano em processo de desenvolvimento de habilidades técnicas (inerentes à especificidade da área em habilitação) e pedagógicas (inerentes aos processos didáticos voltados aos saberes e fazeres docentes), mas também, de construção de competências sociocognitivas. Ao educador, ser humano habilitado pedagogicamente, se atribui à mediação do processo de construção do conhecimento, impondo, portanto, a função de ordenar situações educativas, que o responsabilizam pela implementação de práticas promotoras à humanização e qualidade sobre as relações intra e interpessoais. Os professores são protagonistas no terreno da grande obra, 
a escola ou a Universidade, assumindo o ofício de promover a educação; ao fazê-lo, criam condições para a valorização das suas funções. A responsabilidade em qualificar, de forma técnica e humana, os processos educativos, portanto, não prescindem apenas, mas também, da certificada intervenção docente. Uma formação docente consistente, que passe a manifestar compromisso social, cultura profissional, habilidade pedagógica e conhecimento contribuirá, de maneira efetiva, à qualidade educacional. Desde meados do século XX, o ensino não sofreu grandes transformações estruturais tão significativas como as de outras profissões. O processo educativo escolar impõe ao educador, compromisso amplo e determinante à formação do sujeito individual e social, tornando-o refém de uma responsabilidade, que tem princípio nos primeiros anos da educação formal, balizando habilidades, conceitos e atitudes, que respaldam a continuidade dos estudos em tempo de aprendizagem escolar e acadêmica, e, o colocando como tutor ao cauteloso pacto de formar para as humanidades.

\section{CONCLUSÃO}

Este artigo buscou apresentar as narrativas dos estudantes universitários, licenciandos de Curso de Formação de Professores, diante de vivências interventoras, de caráter extensionista. A extensão desenvolvida na Universidade Franciscana, sobre uma dimensão dialógica e compartilhada entre instituições, que educam, sejam então, Universidade e Comunidade, ganham cada vez mais ingredientes de compromisso social e contribuições à formação acadêmica e profissional dos estudantes, que intervém, de forma pró-ativa sobre os territórios educacionais.

As narrativas anunciadas expressam a percepção amadurecida e argumentada, que os acadêmicos já tem construído, a partir de uma avaliação crítica e reflexiva, diante de seus próprios percursos formativos, evidenciando assim, as recompensas, que estas ingerências têm promovido à sua vida universitária.

\section{REFERÊNCIAS}

ALARCÃO M. Escola reflexiva e nova racionalidade. Porto Alegre: Artmed, 2001.

CHAUÍ, M. Escritos sobre a universidade. São Paulo: UNESP, 2001.

CONSTITUIÇÃO DA REPÚBLICA FEDERATIVA DO BRASIL. Constituição de 1988. 33. ed., Saraiva, 2004.

FREIRE, P. Extensão ou comunicação? Trad. de Rosisca Darcy de Oliveira. Prefácio de Jacques Chonchol. 7. ed. Rio de Janeiro: Paz e Terra, 1983. 
GADOTTI, M.; CARNOY, M. (org.). Reinventando Freire: a práxis do Instituto Paulo Freire. SP: Instituto Paulo Freire. Lemann Center/ Stanford Graduate School of Education, 2018.

LIBÂNEO, J. C. Os métodos de ensino. São Paulo: Cortez, 1994.

LAMPERT, E. (org.). A universidade na virada do século XXI: ciência, pesquisa e cidadania. Porto Alegre: Sulina, 2000.

MELlO C. M. NETO J. R. M. A. Curricularização da Extensão Universitária. Rio de Janeiro: Freitas Bastos, 2020.

MINISTÉRIOS DA EDUCAÇÃO. Da concepção, das diretrizes e dos princípios, 2018. Disponível em: https://bit.ly/2Xs0Op4. Acesso em: 30 maio 2021.

NÓVOA, A. Os Professores e a sua Formação. Lisboa: Nova Enciclopédia, 1992.

ORLANDI, E. P. Análise do discurso: princípios e procedimentos. Campinas: Pontes, 2005.

RIBEIRO, A. E. Textos multimodais: leitura e produção. São Paulo: Parábola, 2016.

ROSA, G. Primeiras Estórias. Rio de Janeiro: Nova Fronteira, 1962.

SOUZA, E. C. Pesquisa narrativa e escrita (auto) biográfica: interfaces metodológicas e formativas. In: SOUZA, E. C.; ABRAHÃO, M. H. B. (orgs.) Tempos, narrativas e ficções: a invenção de si. Porto Alegre: Edipucrs, 2006. p. 135-147. 